\title{
Maternal Anemia and Fetal Birth Weight; a comparative, cross- sectional, multi-centric study.
}

1. Final Year MBBS (Student) Allama lqbal Medical College Lahore.

2. Fourth Year MBBS (Student) Faisalabad Medical University, Faisalabad.

3. MBBS

House Officer

Holy Family Hospital Rawalpindi

4. FCPS

HOD Medicine

PNS Hafeez Islamabad.

5. Fourth Year MBBS (Student) Faisalabad Medical University, Faisalabad.

6. Fourth Year MBBS (Student) King Edward Medical University, Lahore.

Correspondence Address: Dr. M. Ahmad Mustansir Allama Iqbal Medical College Lahore. ahmadbutt250@gmail.com

Article received on:

04/11/2020

Accepted for publication: 01/02/2021
M. Ahmad Mustansir ${ }^{1}$, Abdul Rafae Faisal ${ }^{2}$, Isbah Tauqir ${ }^{3}$, Faisal Naveed Akhtar ${ }^{4}$, Pramod Singh $^{5}$, Usamah Saeed Butt ${ }^{6}$

ABSTRACT... Objective: The objective of this study is to evaluate the relationship between maternal anemia and fetal birth weight and how other variables impact fetal birth weight. Study Design: Comparative, Cross-sectional, Multi-centric study. Setting: Labor Room Jinnah Hospital Lahore, Labor Room Allied Hospital Faisalabad, Labor Room Holy Family Hospital Rawalpindi. Period: $01-08-2020$ to 31-10-2020. Material \& Methods: The data for this comparative, crosssectional, multi-centric study was collected using a structured questionnaire from 360 subjects with equal representation among 3 major tertiary care centers of Punjab, Pakistan. Sample size was calculated using Open-Epi software at 95 percent confidence interval, taking frequency of anticipated factor (frequency of LBW babies among anemic females) as 64 percent. The calculated sample was 353 and we recruited 360 subjects for the study. 120 subjects from each study setting were recruited and divided into anemic and non-anemic groups of 60 subjects each. The sample size was equally divided among anemic and non-anemic groups to achieve comparative analysis of both groups for a variety of variables. Data analysis was performed on $\mathrm{R}$ v 4.0.2. Results: This study demonstrated a significant association between maternal anemia and low fetal Birth weight. In Anemic group, $28.88 \%$ of the babies were born with Low Birth weight, as compared to $17.77 \%$ Low Birth weight babies in the Non-Anemic group, the difference being statistically significant $(p<0.012)$. Conclusion: Maternal anemia and fetal birth weight have a significant negative correlation. Mothers with Anemia are more likely to give birth to babies with Low weight at Birth.

Key words: $\quad$ Anemia, Fetal Birth Weight, Low Birth Weight, Maternal.

Article Citation: Mustansir MA, Faisal AR, Tauqir I, Akhtar FN, Singh P, Butt US. Maternal Anemia and Fetal Birth Weight; a comparative, cross-sectional, multicentric study. Professional Med J 2021; 28(8):1190-1195. https://doi.org/10.29309/TPMJ/2021.28.08.6191

\section{INTRODUCTION}

Anemia is global public health problem and affects 1.62 billion people worldwide, which equates to $24.8 \%$ of the global population. ${ }^{1}$ The WHO criteria for diagnosis of anemia in pregnancy is a hemoglobin $(\mathrm{Hb})$ level of $<11 \mathrm{~g} /$ dL. ${ }^{1}$ According to $\mathrm{WHO}$, a birthweight of $<2500 \mathrm{~g}$ is considered a low birth weight (LBW). Around 20 million low birthweight babies are born annually, mostly in low- and middle-income countries such as Pakistan. ${ }^{2}$ Anemia is considered to be a cause of significant morbidity and mortality in the world but gestational anemia is detrimental to health of the mother and the baby and therefore poses a more significant threat to public health authorities. Gestational anemia is responsible for the death of 115000 mothers and 590000 perinatal baby's annually. ${ }^{3}$

Moreover, LBW babies are at a high risk for developing malnutrition, under nutrition and various infections during neonatal period. ${ }^{4}$ It is therefore important to investigate how maternal anemia affects fetal birth weight, especially in developing countries such as Pakistan with nascent health care services. In Pakistan, 39.1\% of the pregnant women suffer from anemia according to WHO estimates. ${ }^{1}$ The major causes of anemia include poor diet, Vitamin B12 and Folic Acid deficiency, and to some extent worm infestations. According to Pakistan Health and Demographic Survey, more than one-fifth of the babies, weighed after birth had a birth Weight lower than $2.5 \mathrm{~kg} .{ }^{5}$ However, the 
effect of maternal anemia on fetal birth weight has not been investigated in proportion to the prevalence of maternal anemia and LBW babies in our population. A study in Ethiopia found that anemic mothers were more likely to deliver LBW babies. ${ }^{2}$ A study in Rawalpindi found a significant association between maternal anemia and low fetal birth weight. ${ }^{6}$

However, there is the lack of a comprehensive multi-centric studies that can form a clear association between maternal anemia and low birth weight. Our study divides subjects into equal anemic and non-anemic groups and seeks to measure the incidence of LBW babies in each group, and to appreciate a significant difference, if any, in the incidence of LBW babies in both the groups.

\section{Operational Definitions}

1. Anemia: Blood Hemoglobin levels, less than $11 \mathrm{~g} / \mathrm{dL}$ is diagnostic of anemia in pregnancy. ${ }^{1}$

2. Birth weight is measured by weighing scale immediately after baby birth, a weight less than $2500 \mathrm{~g}$ is low birth weight.

3. Mild anemia is diagnosed at a $\mathrm{Hb}$ level of 10.0$10.9 \mathrm{mg} / \mathrm{dl}$. Moderate anemia is diagnosed at an $\mathrm{Hb}$ level of $7.0-9.9 \mathrm{mg} / \mathrm{dl}$ while severe anemia is diagnosed at an $\mathrm{Hb}$ level below 7.0 $\mathrm{mg} / \mathrm{dl}^{7}$

\section{MATERIAL \& METHODS}

It was a comparative, cross-sectional multi-centric study conducted at Labor Room Jinnah Hospital Lahore, Labor Room Allied Hospital Faisalabad, Labor Room Holy Family Hospital Rawalpindi. 0108-2020 to 31-10-2020.

Sample size was calculated using open epi software at 95 percent confidence interval taking margin of error as 5 percent and frequency of anticipated factor (frequency of LBW babies among anemic females) as 64 percent. The calculated sample was 353 and we recruited 360 subjects for the study. 120 subjects from each study setting were recruited by non-probability, purposive sampling and divided into anemic and non-anemic groups of 60 subjects each.
All pregnant females 16 years or older with a singleton pregnancy and complete medical record were included in the study. The subjects will be divided into two groups, anemic group with $\mathrm{Hb}$ levels less than $11 \mathrm{~g} / \mathrm{dL}$ and non-anemic group with $\mathrm{Hb}$ levels greater than or equal to 11 $\mathrm{g} / \mathrm{dL}$.

All subjects with a past history of gynecological disease, obstetric complications and any other medical illness, other than anemia, were excluded for confounding factors. Subjects with a history of hemorrhage in the last 48 hours were also excluded.

The data on anemic status was collected via a structured questionnaire to exclude all the confounding factors. $\mathrm{Hb}$ levels through a Complete Blood Count (CBC) was used to determine the anemic status of the subject. The birth weight of the baby born to each subject was routinely measured in the Labor room as part of the protocol.

Data was analyzed with $R$ v 4.0.2 and was used to measure frequency of LBW babies in the total number of babies in each group, as well as the Mean Fetal birth weight in anemic and NonAnemic group of patients. ANOVA, T-Test, and Karl Pearson tests were used for data analysis and $p$ value less than $0.05(p<0.05)$ was used to denote statistically significant difference. The research was approved by the relevant Ethical review board Ref No. 65 $5^{\text {th }}$ ERB.

\section{RESULTS}

The results of the research are summarized in Table-I, Table-II, and Figure-1. Table-I is a summary of socio-demographic profile, anemic status and other relevant information about the respondents. The data was collected from three Tertiary care hospitals across Punjab. The data was collected in such a way that $50 \%$ of the respondents were anemic. Out of 180 anemic patients, 113 had moderate level of anemia, 4 had severe and 63 patients presented with mild anemia. Most of the patients, $73.1 \%$, had secondary level of education or below, with only $3.9 \%$ working outside from home. $55.8 \%$ of the patients used 
iron supplements during pregnancy and $67.2 \%$ of the patients gave birth via Cesarean Section.

Table-II gives a comparative analysis of fetal birth weight (FBW) with factors suspected to have an influence on the magnitude of FBW. Mean FBW among the anaemics was found to be 2929.4g, while non-anaemics had a mean FBW of $3084.9 \mathrm{~g}$. The mean difference among the two groups varied significantly $(t=-1.99, p=0.047$ ). While parity did not show significant correlation with FBW, abortive history had a significant negative association $(r=-0.117, p=0.027)$ with FBW, with FBW decreasing in patients having higher frequency of previous abortions. This is also illustrated in Figure A. In addition, antenatal status also significantly $(p<0.022)$ had an impact on mean FBW, with mothers who accessed health care services giving birth to fetuses with more mean FBW $(x \square=3094.6)$ than those who did not $(x \square=2912.6)$. Age, Educational Status and Monthly Household Income did not significantly influence FBW. MCV, iron supplementation during pregnancy, and mode of delivery also did not have significant association with FBW.
Frequency (\%)

Education level

Matriculation or below Intermediate or below Bachelors or above

Working status

Housewife

Working

Antenatal status

Booked

Unbooked

Blood transfusion in pregnancy

Yes

No

$263(73.1 \%)$

$52(14.4 \%)$

$40(11.1 \%)$

$341(94.7 \%)$

$14(3.9 \%)$

Iron supplementation in pregnancy

Yes

No

$86(51.7 \%)$

$172(47.8 \%)$

$24(6.7 \%)$

$336(93.3 \%)$

$201(55.8 \%)$ $159(44.2 \%)$

History of anemia in pregnancy

Yes

No

$163(45.3 \%)$

$197(54.7 \%)$

Level of anemia

Non-anemics

$180(50 \%)$

Mild

Moderate

Severe

$63(17.5 \%)$

$113(31.4 \%)$

$4(1.1 \%)$

Mode of delivery

Vaginal

C-section

$115(31.9 \%)$

242 (67.2)

Table-I. Socio-Demographic Profile and Relevant Information of Respondents.

\begin{tabular}{|c|c|c|c|}
\hline & Test-performed & Test Statistic & P-Value \\
\hline Age & Karl-Pearson correlation & $r=0.0100$ & 0.8498 \\
\hline MCV & Karl-Pearson correlation & $r=-0.003$ & 0.9515 \\
\hline Educational Status & ANOVA & $F=2.438$ & 0.0643 \\
\hline Monthly household income & Kar-Pearson correlation & $r=0.0837$ & 0.1361 \\
\hline Blood transfusion during pregnancy & T-test & $t=0.091$ & 0.9275 \\
\hline Iron supplementation & T-test & $t=-0.170$ & 0.865 \\
\hline Mode of delivery & ANOVA & $F=0.09$ & 0.914 \\
\hline Antenatal status & $\begin{array}{c}\text { T-test } \\
\text { Mean in booked }=3094.6 \mathrm{~g} \\
\text { Mean in unbooked }=2912.6 \mathrm{~g}\end{array}$ & $t=2.3004$ & $0.02213^{*}$ \\
\hline Parity & Karl- Pearson & $r=-0.044$ & 0.399 \\
\hline Abortion history & Karl-Pearson & $r=-0.117$ & $0.027^{\star}$ \\
\hline Anemic status & $\begin{array}{c}\text { T-test } \\
\text { Mean in anemic }=2929.4 \mathrm{~g} \\
\text { Mean in non-anemic }=3084.9 \mathrm{~g}\end{array}$ & $\mathrm{t}=-1.9928$ & $0.047^{\star}$ \\
\hline
\end{tabular}




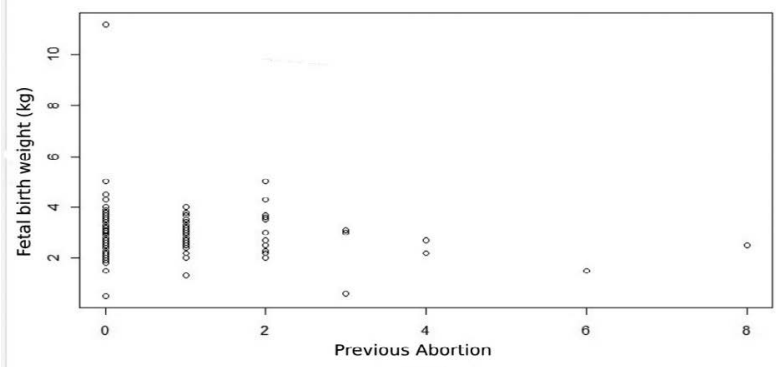

Figure-1. Scatterplot (Fetal birth weight Vs Previous Abortion).

\section{DISCUSSION}

Anemia in pregnancy, defined by $\mathrm{WHO}$ as hemoglobin level less than $11.0 \mathrm{mg} / \mathrm{dl},{ }^{1}$ is associated with significant morbidity and mortality for maternal and neonatal health with effects ranging from breathing difficulties and palpitations to pre-eclampsia and intrauterine growth retardation. ${ }^{8}$ The global burden of anemia is 1.62 billion people and it roughly affects a quarter of human population (24.8\%). ${ }^{1}$ In fact, $48.2 \%$ of the pregnant women in South-East Asia suffer from anemia during pregnancy, which is a significant public health concern. ${ }^{1}$ On the other hand, low birthweight is a significant problem in developing world, with $28 \%$ babies born in South Asia having low birthweight. ${ }^{2}$ Mortality rate of low birthweight is up to 20 times as much as babies born with at least $2.5 \mathrm{~kg}$ birthweight and they are thought to suffer more at the hands of chronic conditions such as diabetes mellitus and hypertension in adult life. ${ }^{2,9}$ In the light of this evidence of widespread prevalence, it becomes imperative to investigate the relationship, if any, between maternal anemia and fetal birthweight.

The purpose of our study was to investigate whether a significant difference in birthweight exists between data obtained from anemic and non-anemic groups of pregnant women. The mean age of mothers in the anemic group was 26.74 years compared to 26.55 years in nonanemic group, and the difference between maternal age is statistically insignificant. These values are comparable to a study done in the past where the difference was statistically insignificant as well (29.44 vs 27.98). ${ }^{6}$ The mean fetal birthweight in anemic group was calculated as $2.92 \mathrm{kgs}$ as compared to $3.08 \mathrm{kgs}$ in non-anemic group with the difference being statistically significant ( $p: 0.047)$. It shows that presence of maternal anemia causes a significant decrease in fetal birthweight as an independent factor and this finding is in line with the results of similar investigations. ${ }^{2,9-14}$ In addition, our analysis showed that $28.88 \%$ babies born in the anemic group were low birthweight, as compared to $17.77 \%$ babies being low birthweight in nonanemic group, the difference being statistically significant ( $p: 0.012)$. This finding is partially supported by a study done in Pakistan. The study found out that $64 \%$ percent of the babies born in the anemic group were low birthweight, while $10 \%$ of the babies born in the non-anemic group were low birthweight, the difference being statistically significant $(p<0.001) .{ }^{6}$ The difference in the percentages recorded in the aforementioned past study are most likely due to smaller study population, single center used for data collection, and the use of entitled subjects for the study. Our multi-centric study is centered in three major tertiary care hospitals of Pakistan and therefore its data can be projected to national as well as regional level for policy making and public health Interventions.

The prevalence statistics of anemia in our study subjects is as follows, $35.0 \%$ had mild anemia, $31.4 \%$ had moderate, and $1.1 \%$ suffered from severe anemia. $52.2 \%$ of the anemic patients took treatment for anemia i.e. iron supplementations/ blood transfusions. These findings are in agreement with a study from Assam, India where the recorded values for prevalence of anemia in study subjects were, $29.8 \%$ mild, $32.8 \%$ moderate and $2.1 \%$ suffered from severe anemia. ${ }^{15}$ This similarity can be explained by geographical proximity, cultural practices and socioeconomic situation in Pakistan and India.

Our study found that a history of previous abortion negatively affected the fetal birthweight, with progressive abortions causing a reduction in fetal birthweight in subsequent pregnancies. In fact, the difference in fetal birthweight between patients with history of abortion and patients without history of abortion is statistically significant 
(p: 0.027). These findings are in agreement with studies done at both international (USA) ${ }^{16}$ and local level (Peshawar, Pakistan). ${ }^{17}$ Our study also found out that the mean birth weight in the booked patients (registered with respective hospitals before delivery) was 3.09 kgs, as compared to mean birth weight in the unbooked patients (not registered with respective hospitals before delivery) $2.91 \mathrm{kgs}$, the difference being statistically significant ( $p: 0.02$ ). This finding acts in concert with a similar finding in a study based in Peshawar, Pakistan. ${ }^{17}$

Anemia in pregnancy is associated with preterm birth, maternal mortality and poor perinatal outcome $^{3}$. Our study makes it clear that there is a clear association between maternal anemia and low birth weight and hence based on our observations, National and regional recommendations can be made to prevent and reduce the prevalence of maternal anemia to reduce low fetal birthweight and its associated complications.

As part of the data was self-reported, it is subject to recall bias. Moreover, the data was recorded by different collectors from each center so, it is subject to observer bias as well. Nevertheless, the close-ended nature of the questionnaire reduced it to the minimum.

\section{CONCLUSION}

This multi-centric study shows that maternal anemia is significantly associated with low fetal birthweight. Similarly, the severity of anemia intensifies this very phenomenon. Furthermore, we found abortive history to have a negative and antenatal booking status to have a positive effect on fetal birthweight.

\section{RECOMMENDATION}

LBW babies face a reduced chance of survival and more pediatric complications as compared to babies born with a normal birth weight. This problem is still a significant public health issue in the developing world with future generations at stake. We recommend that this problem should be addressed through awareness campaigns and active interventions at the local, regional and international scale. We recommend that Anemia should be screened in Pre-conception females of reproductive age before it adversely affects Fetal Birth weight. We also recommend that Serum Ferritin level be used for workup of maternal anemia in antenatal setups to ensure an earlier diagnosis and treatment.

Copyright@ 01 Feb, 2021.

\section{REFERENCES}

1. World Health Organization. Worldwide prevalence of anemia 1993-2005: WHO global database on anemia.

2. Girma S, Fikadu T, Agdew E, Haftu D, Gedamu G, Dewana Z, Getachew B. Factors associated with low birthweight among newborns delivered at public health facilities of Nekemte town, West Ethiopia: A case control study. BMC pregnancy and childbirth. 2019 Dec 1; 19(1):220.

3. Kumari S, Garg N, Kumar A, Guru PK, Ansari S, Anwar S, Singh KP, Kumari P, Mishra PK, Gupta BK, Nehar S. Maternal and severe anemia in delivering women is associated with risk of preterm and low birth weight: A cross sectional study from Jharkhand, India. One Health. 2019 Dec 1; 8:100098.

4. Bodeau-Livinec $F$, Briand V, Berger J, Xiong X, Massougbodji A, Day KP, Cot M. Maternal anemia in Benin: Prevalence, risk factors, and association with low birth weight. The American journal of tropical medicine and hygiene. 2011 Sep 1; 85(3):414-20.

5. National Institute of Population Studies, Pakistan. Pakistan demographic and health survey 2017-18. Pakistan demographic and health survey 2017-18. 2019.

6. Ahmad MO, Kalsoom U, Sughra U, Hadi U, Imran M. Effect of maternal anemia on birth weight. Journal of Ayub Medical College Abbottabad. 2011 Mar 1; 23(1):77-9.

7. World Health Organization. Haemoglobin concentrations for the diagnosis of anemia and assessment of severity. World Health Organization; 2011.

8. Abu-Ouf NM, Jan MM. The impact of maternal iron deficiency and iron deficiency anemia on child's health. Saudi medical journal. 2015; 36(2):146.

9. Khan A, Nasrullah FD, Jaleel R. Frequency and risk factors of low birth weight in term pregnancy. Pakistan journal of medical sciences. 2016 Jan; 32(1):138. 
10. Lone FW, Qureshi RN, Emmanuel F. Maternal anemia and its impact on perinatal outcome in a tertiary care hospital in Pakistan. Eastern Mediterranean Health Journal. 2004; 10(6):801.

11. Figueiredo AC, Gomes-Filho IS, Batista JE, Orrico GS, Porto EC, Cruz Pimenta RM, dos Santos Conceição S, Brito SM, Ramos MD, Sena MC, Vilasboas SW. Maternal anemia and birth weight: A prospective cohort study. PloS one. 2019 Mar 18; 14(3):e0212817.

12. Rahmati S, Delpisheh A, Parizad N, Sayehmiri K. Maternal anemia and pregnancy outcomes: A systematic review and meta-analysis. International journal of pediatrics. 2016 Aug 1; 4(8):3323-42.

13. Patel A, Prakash AA, Das PK, Gupta S, Pusdekar YV, Hibberd PL. Maternal anemia and underweight as determinants of pregnancy outcomes: Cohort study in eastern rural Maharashtra, India. BMJ open. 2018 Aug 1; 8(8):e021623.
14. Muftah S. Maternal under-nutrition and anemia factors associated with low birth weight babies in Yemen. Int J Community Med Public Health. 2016 Oct; 3:2749-56.

15. Nair M, Choudhury MK, Choudhury SS, Kakoty SD, Sarma UC, Webster P, Knight M. Association between maternal anemia and pregnancy outcomes: A cohort study in Assam, India. BMJ Global Health. 2016 Apr 1; $1(1)$.

16. Brown JS, Adera T, Masho SW. Previous abortion and the risk of low birth weight and preterm births. Journal of Epidemiology \& Community Health. 2008 Jan 1; 62(1):16-22.

17. Badshah S, Mason L, McKelvie K, Payne R, Lisboa PJ. Risk factors for low birthweight in the publichospitals at Peshawar, NWFP-Pakistan. BMC public health. 2008 Dec 1; 8(1):197.

\begin{tabular}{|c|c|c|c|}
\hline \multicolumn{4}{|c|}{ AUTHORSHIP AND CONTRIBUTION DECLARATION } \\
\hline Sr. \# & Author(s) Full Name & Contribution to the paper & Author(s) Signature \\
\hline 2 & M. Ahmad Mustansir & $\begin{array}{l}\text { Report Writing and Data } \\
\text { Collection. } \\
\text { Data Collection, Literature } \\
\text { Search. }\end{array}$ & $\begin{array}{l}\text { Ange } \\
\text { Rus }\end{array}$ \\
\hline 3 & Isbah lauqır & Data Collection. & \\
\hline 4 & Faisal Naveed Akhtar & $\begin{array}{l}\text { Conceptualization and } \\
\text { Proof reading. }\end{array}$ & \\
\hline 5 & Pramod Singh & Data alaysis. & EDol \\
\hline 6 & Usamah Saeed Butt & Literature Search. & USh \\
\hline
\end{tabular}

